\title{
Multinational Internet-based survey of patient preference for newer oral or injectable Type 2 diabetes medication
}

This article was published in the following Dove Press journal:

Patient Preference and Adherence

2 November 2010

Number of times this article has been viewed

\section{Marco daCosta \\ DiBonaventura' \\ Jan-Samuel Wagner' \\ Cynthia J Girman ${ }^{2}$ \\ Kimberly Brodovicz ${ }^{2}$ \\ Qiaoyi Zhang ${ }^{3}$ \\ Ying Qiu ${ }^{3}$ \\ Sri-Ram Pentakota ${ }^{3}$ \\ Larry Radican ${ }^{3}$}

'Health Sciences Practice, Kantar Health, New York; ${ }^{2}$ Epidemiology,

${ }^{3} \mathrm{Global}$ Health Outcomes,

Merck, Whitehouse Station,

New Jersey, USA
Correspondence: Marco DiBonaventura Health Sciences Practice, Kantar Health, II Madison Avenue, I2th Floor, New York, NY 10010 , USA

Tel + I 2127063988

Fax + I 2126477659

Email marco.dibonaventura@ kantarhealth.com
Background: The prevalence of Type 2 diabetes mellitus continues to rise. Although glucagon-like peptide-1 (GLP-1) analog and dipeptidyl peptidase-4 (DPP-4) inhibitor medications are effective, there are differences between these products, including method of administration (injectable versus oral). The objective of this study was to examine patient preferences (and predictors of preferences) for two different medication profiles, one similar to a GLP-1 analog (liraglutide) and another similar to a DPP-4 inhibitor (sitagliptin).

Methods: Internet survey data were collected in two waves (wave 1, $n=2402$; wave 2, $n=1340$ ) using patients from the US and Europe. Patients were presented with two hypothetical medication profiles ("drug A" and "drug B", resembling sitagliptin and liraglutide, respectively) and asked to report their preferences.

Results: Most patients in wave 1 and wave 2 reported that overall they would prefer a drug with the sitagliptin-like profile ( $81.9 \%$ and $84.4 \%$, respectively) over a drug with the liraglutide-like profile ( $18.1 \%$ and $15.6 \%$, respectively), and $>80 \%$ of patients reported that they would be able to take a drug with the sitagliptin-like profile as directed by their physician for a longer period. The likelihood of preferring the sitagliptin-like profile significantly increased as age (odds ratio $[\mathrm{OR}]=1.02$ ) and importance placed on method of administration $(\mathrm{OR}=1.32)$ increased $(P<0.05)$. Although the sitagliptin-like profile was preferred by the majority of patients in all subgroups, a lower proportion of patients with obesity, with weight gain, with $\mathrm{A}_{1 \mathrm{C}}$ values above target, and who exercised preferred the sitagliptin-like profile compared with those without obesity ( $77.0 \%$ versus $87.9 \%)$, without weight gain $(77.8 \%$ versus $86.7 \%)$, with $\mathrm{A}_{1 \mathrm{C}}$ values at or below target $(79.0 \%$ versus $86.5 \%)$, and who did not exercise $(81.6 \%$ versus $86.4 \%)$, respectively $(P<0.05)$.

Conclusions: This research suggests that patients (across geographies) prefer an oral medication with a profile resembling sitagliptin to an injectable medication with a profile resembling liraglutide.

Keywords: Type 2 diabetes, medication preference, sitagliptin, liraglutide

\section{Introduction}

Type 2 diabetes mellitus (T2DM) is considered to be a major epidemic worldwide. ${ }^{1}$ According to the International Diabetes Federation, the prevalence of diabetes is currently estimated at $8.5 \%$ in Europe and $11.7 \%$ in North America and the Caribbean, with prevalence expected to rise to $10.0 \%$ and $13.6 \%$, respectively, by $2030 .{ }^{1}$ As prevalence figures rise, so do health care costs. The American Diabetes Association previously estimated that diabetes was responsible for $\$ 116$ billion in direct medical costs and $\$ 58$ billion in indirect costs in the US in $2007 .^{2}$ 
As a result of the United Kingdom Prospective Diabetes Study (UKPDS) and other studies, guideline committees have recommended that patients with TD2M maintain a hemoglobin $\mathrm{A}_{1 \mathrm{C}}$ level of less than 7\%. ${ }^{3,4}$ For many patients with T2DM, oral antihyperglycemic agents are used as first-line therapies because of the combination of efficacy and physicians' perceptions of patient preference. ${ }^{5,6}$ Some oral antihyperglycemic agents have been associated with adverse events, such as weight gain and hypoglycemia, which have been linked to nonadherence, treatment dissatisfaction, and diminished health-related quality of life (HRQoL). ${ }^{7-9}$ Partly as a consequence, persistence with first-line oral antihyperglycemic agents has been poor, with estimates in the T2DM managed care population ranging from $34 \%$ to $60 \%$ for discontinuation after 12 months. ${ }^{10,11}$

Dipeptidyl peptidase-4 (DPP-4) inhibitors and glucagonlike peptide-1 (GLP-1) mimetics or analogs, which rely on the gastrointestinal hormones that are part of the incretin system for the treatment of T2DM, provide a therapeutic alternative to common oral antihyperglycemic agents (eg, sulfonylureas, thiazolidinediones). These newer medications may be particularly useful in cases where other therapies are not well tolerated or as complementary therapies when ongoing therapies do not allow the patient to reach their glycemic target. ${ }^{12}$ GLP-1 receptor agonists and DPP-4 inhibitors have been shown to be noninferior to other oral antihyperglycemic agents, lowering mean $\mathrm{A}_{1 \mathrm{C}}$ levels by $0.97 \%$ and $0.74 \%$, respectively. ${ }^{13}$ Additionally, hypoglycemic episodes and weight gain, reported with other oral antihyperglycemic agents, are infrequent or absent with these new agents. ${ }^{14}$

Despite both targeting the incretin system, GLP-1 receptor agonists and DPP-4 inhibitors do have several differences. First, all GLP-1 receptor agonists are injectable medications. Previous studies have shown that patients prefer additional oral agents over injectable agents because of fear of injections and the desire to avoid them. ${ }^{6,15,16}$ Moreover, one study found that persistence with these agents was poor, with only $28.7 \%$ treatment continuation at one year follow-up among treatment-naïve patients with T2DM. ${ }^{17}$ Second, some GLP-1 receptor agonists may have efficacy and weight advantages over DPP-4 inhibitors, suggesting a possible relationship with improved HRQoL because previous studies have shown an association between weight loss and HRQoL. ${ }^{16,18,19}$ Third, patients on GLP-1 therapies have reported higher rates of gastrointestinal-related complications, including nausea and vomiting, compared with DPP-4 inhibitors. ${ }^{18,20}$

Although incretin-based medications may potentially help to overcome some of these barriers to successful T2DM management, the positive and negative effects of these drugs should be further analyzed in the context of patient preference to assess the likelihood of long-term patient acceptability. Although physicians play a crucial role in determining the best therapeutic intervention for their patients, patient preferences should also be considered. The achievement of glycemic control goals rely to a large extent on treatment compliance and adherence. The objective of the current study was to examine patient preferences when presented with profiles similar to a GLP-1 analog (liraglutide) and a DPP-4 inhibitor (sitagliptin).

\section{Patients and methods}

\section{Recruitment}

Data were collected in two waves with patients from the US, France, Italy, Germany, Spain, and the UK. Patients were recruited from the 2008 and 2009 US National Health and Wellness Survey (NHWS), an annual Internet-based questionnaire developed by Consumer Health Sciences/Kantar Health, and the Ailment Panel of Lightspeed Research. These panels are designed to be nationally representative and mimic the demographic composition of each country's total adult population. Further details of the methodology and comparisons between NHWS and other sources have been described elsewhere. ${ }^{21}$ Participants who were over the age of 18 years, diagnosed with T2DM by a health care professional, used only metformin monotherapy to treat their diabetes, and provided informed consent were eligible to participate in the study. The study protocol was approved by the Essex Institutional Review Board.

Wave 1 was conducted between June 2009 and July 2009, and wave 2 was conducted between December 2009 and January 2010. All patients who completed the first wave $(\mathrm{n}=2402)$ were recontacted and asked to participate in the second wave ( $\mathrm{n}=1340,56.8 \%$ response rate). The second wave was conducted because newer data became available after wave 1 from a head-to-head trial of sitagliptin and liraglutide (Novo Nordisk Interim Financial Report, August 6, 2009). The $A_{1 \mathrm{C}}$ efficacy difference reported in the head-to-head trial $(0.6 \%)$ was twice that assumed in wave 1 , which had been based on data from two different clinical trials of sitagliptin and liraglutide. ${ }^{22,23}$ Data from the head-to-head trial on glycemic efficacy and weight loss were used for the medication profiles in wave 2. However, because neither gastrointestinal side effect nor blood pressure data from the head-to-head trial were provided in the Novo Nordisk report, data from Nauck et al were used for gastrointestinal tolerability and blood pressure effects. ${ }^{22,23}$ The Novo Nordisk report noted that the safety data of liraglutide in the head-to-head study were comparable with what was observed in previous clinical studies of liraglutide. 
Therefore, it was deemed acceptable to use data from both trials in constructing the profiles. Only side effects or other effects that were statistically significant or clinically meaningful in the trials were included in the profiles.

Although the head-to-head trial suggested that sitagliptin was associated with a small weight loss of $1 \mathrm{~kg}$, it was decided conservatively to assume no weight loss for sitagliptin in the profile. Finally, $\mathrm{A}_{1 \mathrm{C}}$ baseline values were converted to average blood glucose values based on a published equation. ${ }^{24}$ It was assumed that patients would better comprehend blood glucose values, which are based upon day-to-day self monitoring, as opposed to $\mathrm{A}_{1 \mathrm{C}}$ values, which are periodically tested laboratory measures.

\section{Measures}

\section{Medication preference variables}

Patients were shown two medication profiles at each wave of the study (Table 1), one of which was similar to the profile of sitagliptin (noted only as "drug A" to the patients) and the other of which was similar to liraglutide (only noted as “drug B"). Patients were given the following instructions: "Below are hypothetical descriptions of two medications that treat Type 2 diabetes-drug A and drug B (Note: neither one is an insulin). Assume taking metformin alone does not lower your blood sugar enough and that your physician offers you a choice of either drug A or drug B to be added to your current diabetes therapy of metformin. Assume that both medications cost you the same amount." All patients were asked which they would prefer (drug A or drug B), which they would prefer to take first knowing they could later switch or add on other therapies if needed, and which they would be able to take as directed by their physician for a longer period of time. Additionally, for all patients who preferred drug B or preferred to take drug B first, they were asked whether their preference would change if drug A had been used by physicians and patients for two years and drug B had just become available. The patients were also asked whether their preference would change if drug A cost less than drug B.

Table I Medication profiles shown to patients in wave I and wave 2

\begin{tabular}{|c|c|c|}
\hline & Drug A & Drug B \\
\hline \multicolumn{3}{|l|}{ Wave I } \\
\hline How you take the medication & Oral tablet taken once a day & Injection (needle) self-administered once a day \\
\hline Blood sugar lowering efficacy & $\begin{array}{l}\text { If you have a blood sugar reading of } 183 \text {, taking } \\
\text { this oral medication can lower it to about } 164 \\
\text { (individual results may vary) }\end{array}$ & $\begin{array}{l}\text { If you have a blood sugar reading of } 183 \text {, using this injection } \\
\text { medication can lower it to about } 154 \text { (individual results } \\
\text { may vary) }\end{array}$ \\
\hline Side effects & $\begin{array}{l}\text { Generally similar to a sugar pill with very low } \\
\text { risk of hypoglycemia (ie, low blood sugar) }\end{array}$ & $\begin{array}{l}\text { - Nausea (occurs in II to I9\% of patients), vomiting (occurs } \\
\text { in } 5 \text { to } 7 \% \text { of patients) and diarrhea (occurs in } 8 \text { to I5\% } \\
\text { of patients), which goes away for most patients after } \\
\text { about I month (individual results may vary) } \\
\text { - Other side effects generally similar to a sugar pill with very } \\
\text { low risk of hypoglycemia (ie, low blood sugar) }\end{array}$ \\
\hline Other effects & $\begin{array}{l}\text { - Weight: no change } \\
\text { - Blood pressure: no change }\end{array}$ & $\begin{array}{l}\text { - Weight: loss of about } 6.2 \text { pounds (individual results may vary) } \\
\text { - Blood pressure: decrease in systolic blood pressure of about } \\
2 \text { to } 3 \mathrm{~mm} \text { of mercury }(\mathrm{Hg}) \text { (individual results may vary) }\end{array}$ \\
\hline \multicolumn{3}{|r|}{ 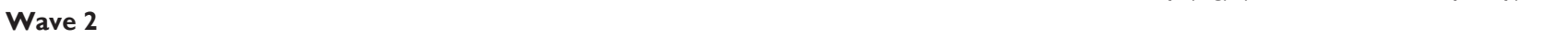 } \\
\hline How you take the medication & Oral tablet taken once a day & Injection (needle) self-administered once a day \\
\hline Blood sugar lowering efficacy & $\begin{array}{l}\text { If you have a blood sugar reading of } 197, \\
\text { taking this oral medication can lower it to } \\
\text { about I7I (individual results may vary) }\end{array}$ & $\begin{array}{l}\text { If you have a blood sugar reading of } 197 \text {, using this } \\
\text { injection medication can lower it to about I } 54 \text { (individual } \\
\text { results may vary) }\end{array}$ \\
\hline Side effects & $\begin{array}{l}\text { Generally similar to a sugar pill with very low } \\
\text { risk of hypoglycemia (ie, low blood sugar) }\end{array}$ & $\begin{array}{l}\text { - Nausea (occurs in II to I9\% of patients), vomiting (occurs } \\
\text { in } 5 \text { to } 7 \% \text { of patients) and diarrhea (occurs in } 8 \text { to I5\% of } \\
\text { patients), which goes away for most patients after about } \\
\text { I month (individual results may vary) } \\
\text { - Other side effects generally similar to a sugar pill with very } \\
\text { low risk of hypoglycemia (ie, low blood sugar) }\end{array}$ \\
\hline \multirow[t]{2}{*}{ Other effects } & - Weight: no change & $\begin{array}{l}\text { - Weight: loss of about } 7.7 \text { pounds (individual results } \\
\text { may vary) }\end{array}$ \\
\hline & - Blood pressure: no change & $\begin{array}{l}\text { - Blood pressure: decrease in systolic blood pressure } \\
\text { of about } 2 \text { to } 3 \mathrm{~mm} \text { of mercury }(\mathrm{Hg}) \text { (individual results } \\
\text { may vary) }\end{array}$ \\
\hline
\end{tabular}

Note: In the EU countries, blood sugar efficacy was displayed as I0.I and 9.1 for drug A and I0.I and 8.5 for drug B in wave I, and I0.9 and 9.5 for drug A and I0.9 and 8.5 for drug B in wave 2. Similarly, weight loss was displayed in kilograms for drug B (2.8 kg in wave I and 3.5 in wave 2). 
These additional questions were asked because, at the time of the surveys, sitagliptin had been available on the market for approximately two years and liraglutide was just being launched, and liraglutide is more costly than sitagliptin.

\section{Reasons for preference}

After participants reported their overall preference for drug A or B and which drug they would prefer to take first, they were asked to rank the importance of the following reasons for their preference: how you take the medication (oral or injection), blood sugar lowering, side effects (nausea, vomiting, and diarrhea), and other effects (weight loss and blood pressure decrease).

\section{Demographics}

Country of residence (US, France, Italy, Germany, Spain, UK), age, gender, race/ethnicity (white versus nonwhite), education (college/university degree versus less than college/ university degree), health insurance (yes versus no), and employment status (full-time, part-time, self-employed, not employed but looking for work, not employed and not looking for work, retired, on disability, student, or homemaker) were assessed for all patients.

\section{Health history}

Patients were asked to report the presence of comorbid dyslipidemia, hypertension, and obesity. Patients also reported any health problems experienced in the last 12 months (cardiovascular event, nausea or vomiting, constipation or diarrhea, weight gain, have not experienced any of the listed problems), diabetes management steps (try to maintain a healthy diet, try to maintain an exercise regimen, use glucose monitor), diabetes educational program participation (yes versus no), date of last $\mathrm{A}_{1 \mathrm{C}}$ test (within the last three months, 4-6 months ago, 7-12 months ago, over a year ago, or never), and what their physician said about their $\mathrm{A}_{1 \mathrm{C}}$ level when last tested (below the target, at the target, higher than the target, physician did not provide test results, or do not remember).

\section{Statistical analysis}

Preferences under each scenario (overall preference, preference if you knew you could switch later, preference for medication you could take longer, preference if drug B had just become available, and preference if drug B was more expensive) were reported for both study waves. All other analyses focused exclusively on the overall preference assessed in study wave 2. Differences between the drug A and B preference groups were analyzed according to demographic and health history variables using Chi-square tests for categoric variables and $t$-tests for continuous variables. Overall preference based on wave 2 data was then assessed in a logistic regression controlling for all demographic and patient characteristic variables, which were associated with preference with a $P<0.20$ in the unadjusted analysis. Attribute importance items were forced into the model, regardless of the unadjusted $P$ value, because these were directly related to preference. All analyses were performed using the SAS software version 9.1.

\section{Results}

In wave 1, 2402 patients completed the survey, comprising 400 patients from each country (with the exception of 402 patients from France). Patients were equally split between male $(\mathrm{n}=1222,50.9 \%)$ and female $(\mathrm{n}=1180,49.1 \%)$, although patients were mostly white $(n=2057,85.6 \%)$, had health insurance $(n=1611,67.1 \%)$, and had less than a college/ university degree $(n=1717,71.5 \%)$. The mean age across the sample was 54.5 (standard deviation $[\mathrm{SD}]=12.7$ ) years.

Based on the medication profiles provided, the majority of patients $(81.9 \%)$ responded that overall they would prefer the drug with the sitagliptin-like profile (drug A) over the drug with the liraglutide-like profile (drug B), prefer to take the drug with the sitagliptin-like profile first $(82.8 \%)$, and believed they could take the drug with the sitagliptin-like profile for longer ( $83.4 \%$, Table 2$)$. Among the patients who preferred the liraglutide-like profile (drug B) overall or preferred to take a drug with the liraglutide-like profile first $(n=292), 63.7 \%$ maintained their preference if told the drug

Table 2 Frequency and percentage of patients who chose each medication under varying scenarios

\begin{tabular}{|c|c|c|c|c|}
\hline & \multicolumn{2}{|c|}{$\begin{array}{l}\text { Drug A } \\
\text { (sitagliptin- } \\
\text { like profile) }\end{array}$} & \multicolumn{2}{|c|}{$\begin{array}{l}\text { Drug B } \\
\text { (liraglutide- } \\
\text { like profile) }\end{array}$} \\
\hline & $n$ & $\%$ & $n$ & $\%$ \\
\hline \multicolumn{5}{|l|}{ Wave I preferences } \\
\hline Which drug would you prefer & 1098 & $81.9 \%$ & 242 & $18.1 \%$ \\
\hline $\begin{array}{l}\text { Which drug would you prefer to } \\
\text { take first if you could switch later }\end{array}$ & 1110 & $82.8 \%$ & 230 & $17.2 \%$ \\
\hline $\begin{array}{l}\text { Which drug could you take for } \\
\text { longer }\end{array}$ & 1117 & $83.4 \%$ & 223 & $16.6 \%$ \\
\hline \multicolumn{5}{|l|}{ Wave 2 preferences } \\
\hline Which drug would you prefer & || $3 \mid$ & $84.4 \%$ & 209 & $15.6 \%$ \\
\hline $\begin{array}{l}\text { Which drug would you prefer to } \\
\text { take first if you could switch later }\end{array}$ & 1139 & $85.0 \%$ & 201 & $15.0 \%$ \\
\hline Which drug could you take for longer & 1159 & $86.5 \%$ & $|8|$ & $13.5 \%$ \\
\hline
\end{tabular}

Note: Significantly more patients preferred drug A in each scenario $(P$ 's $<0.001)$. 
with the liraglutide-like profile had just become available, and $65.1 \%$ maintained their preference if a drug with the liraglutide-like profile was more expensive.

In wave 2 , out of the total sample $(\mathrm{n}=1340), 266$ (19.9\%) participants were from Germany, 111 (8.3\%) were from France, 212 (15.8\%) were from Italy, 208 (15.5\%) were from Spain, 265 (19.8\%) were from the UK, and 278 $(20.8 \%)$ were from the US. The majority of participants were male $(n=713,53.2 \%)$, white $(n=1213,90.5 \%)$, had health insurance $(\mathrm{n}=881,65.7 \%)$, and had less than a college/ university degree $(n=943,70.4 \%)$. The mean age across the wave 2 sample was $55.4(\mathrm{SD}=12.1)$ years. Those who participated in both wave 1 and wave 2 were significantly older (55.4 years versus 53.4 years, respectively, $P<0.001$ ), and more likely to be white $(90.5 \%$ versus $79.5 \%, P<0.001)$ and male ( 53.2 versus $47.9, P=0.01)$ than those who only participated in wave 1 .

Although the glycemic efficacy of the drug with the liraglutide-like profile was improved in the medication profile in wave 2, the preference results were consistent with wave 1. Most patients (84.4\%) responded they would prefer the drug with the sitagliptin-like profile (drug A) over the drug with the liraglutide-like profile (drug B) overall, prefer to take the drug with the sitagliptin-like profile first (85.0\%), and believed they could take the drug with the sitagliptin-like profile longer (86.5\%, Table 2). Among those patients who preferred the liraglutide-like profile overall or preferred to take the drug with the liraglutide-like profile first $(\mathrm{n}=251)$, $57.0 \%$ maintained their preference if told the drug had just become available, and $71.3 \%$ maintained their preference if told the drug was more expensive.

The reasons for the overall preference in wave 2 were then compared between patients who preferred the drug with the sitagliptin-like profile and those who preferred the drug with the liraglutide-like profile (Table 3). "How you take the medication, oral versus injectable" was ranked as the most important reason for their preference by the majority of those who preferred the drug with the sitagliptin-like profile (57.5\%). Conversely, "blood sugar lowering" was ranked as the most important reason for their preference by the majority of those who preferred the drug with the liraglutide-like profile (56.0\%). All reasons were ranked differently between the preference groups. Specifically, for patients who preferred the drug with the sitagliptin-like profile, "how you take the medication" (57.5\% versus $12.9 \%, P<0.001)$ and "side effects" $(17.9 \%$ versus $4.3 \%, P<0.001)$ were significantly more likely to be ranked as the most important reason for their preference. Conversely, for patients who
Table 3 Reasons for preference ranked by importance

\begin{tabular}{lllll}
\hline & \multicolumn{2}{l}{ Ranked Ist } \\
\cline { 2 - 5 } & $\begin{array}{l}\text { Drug A } \\
\text { (sitagliptin-like } \\
\text { profile) }\end{array}$ & $\begin{array}{l}\text { Drug B } \\
\text { (liraglutide- } \\
\text { like profile) }\end{array}$ \\
\cline { 2 - 5 } & $\mathbf{n}$ & $\%$ & $\mathbf{n}$ & $\%$ \\
\hline $\begin{array}{l}\text { How you take the medication } \\
\text { (oral or injection) }\end{array}$ & 650 & $\mathbf{5 7 . 5 \% ^ { a }}$ & 27 & $\mathbf{1 2 . 9 \%}$ \\
$\begin{array}{l}\text { Blood sugar lowering } \\
\begin{array}{l}\text { Side effects (nausea, vomiting, } \\
\text { and diarrhea) }\end{array}\end{array}$ & 261 & $\mathbf{2 3 . 1 \%}$ & 117 & $\mathbf{5 6 . 0} \%^{\mathrm{a}}$ \\
$\begin{array}{l}\text { Other effects (weight loss } \\
\text { and blood pressure decrease) }\end{array}$ & 18 & $\mathbf{1 7 . 9 \% ^ { \mathrm { a } }}$ & 9 & $\mathbf{4 . 3 \%}$ \\
\hline
\end{tabular}

Note: aThe percentage of patients who noted each reason as the most important was significantly different between the two groups $(P<0.00 \mathrm{I})$.

preferred the drug with the liraglutide-like profile, "blood sugar lowering" (56.0\% versus $23.1 \%, P<0.001)$ and "other effects" (26.8\% versus $1.6 \%, P<0.001)$ were significantly more likely to be ranked as the most important reason for their preference.

Group differences were then analyzed between patients with a preference for the drug with the sitagliptin-like profile and patients with a preference for the drug with the liraglutide-like profile (Table 4). Patients who preferred the sitagliptin-like profile were significantly older, and were less likely to be female, be white, have comorbid obesity, have experienced weight gain in the past 12 months, have maintained a healthy diet, have maintained an exercise regimen, have participated in a diabetes educational program, and have higher $\mathrm{A}_{1 \mathrm{C}}$ levels than their targets the last time they were tested (all $P<0.05$ ). Differences among countries and employment groups were also observed (all $P<0.05$ ).

Logistic regression was conducted and included all predictors of overall preference in wave 2 at the $P<0.20$ level, as well as all attribute importance items (Table 5). The likelihood of preferring the sitagliptin-like profile significantly increased with increasing age (odds ratio [OR] $=1.02$, 95\% confidence interval [CI]: 1.01-1.04) or the importance placed on method of administration (oral versus injectable, $\mathrm{OR}=1.32,95 \% \mathrm{CI}: 1.15-1.52$ ). Conversely, the likelihood of preferring the sitagliptin-like profile was significantly lower in those with obesity $(\mathrm{OR}=0.54,95 \% \mathrm{CI}: 0.38-0.75)$, weight gain in the last year (OR $=0.62,95 \% \mathrm{CI}: 0.44-0.87)$, those with an $\mathrm{A}_{1 \mathrm{C}}$ above target $(\mathrm{OR}=0.59,95 \% \mathrm{CI}: 0.41-0.83)$, and those who tried to maintain an exercise regimen $(\mathrm{OR}=0.68$, 95\% CI: 0.49-0.96), compared with those without obesity, without weight gain in the last year, those with $\mathrm{A}_{1 \mathrm{C}}$ at or below target, and those who did not try to maintain an exercise regimen, respectively. Although the odds for preferring 
Table 4 Patient characteristics and overall medication preference

\begin{tabular}{|c|c|c|c|c|c|c|c|}
\hline & \multicolumn{2}{|l|}{ Total } & \multicolumn{2}{|c|}{$\begin{array}{l}\text { Drug A (sitagliptin- } \\
\text { like profile) } \\
n=|| 3 \mid(84.4 \%)\end{array}$} & \multicolumn{2}{|c|}{$\begin{array}{l}\text { Drug B (liraglutide- } \\
\text { like profile) } \\
\mathbf{n}=209(15.6 \%)\end{array}$} & \multirow[t]{2}{*}{$P$} \\
\hline & $\mathbf{n}$ & $\begin{array}{l}\% \text { of total } \\
\text { sample }\end{array}$ & n & Row $\%$ & $\bar{n}$ & Row \% & \\
\hline Country & & & & & & & $<0.001$ \\
\hline Germany & 266 & $19.9 \%$ & 214 & $80.5 \%$ & 52 & $19.5 \%$ & \\
\hline France & 111 & $8.3 \%$ & 99 & $89.2 \%$ & 12 & $10.8 \%$ & \\
\hline Italy & 212 & $15.8 \%$ & 185 & $87.3 \%$ & 27 & $12.7 \%$ & \\
\hline Spain & 208 & $15.5 \%$ & 188 & $90.4 \%$ & 20 & $9.6 \%$ & \\
\hline United Kingdom & 265 & $19.8 \%$ & 205 & $77.4 \%$ & 60 & $22.6 \%$ & \\
\hline United States & 278 & $20.8 \%$ & 240 & $86.3 \%$ & 38 & $13.7 \%$ & \\
\hline Gender & & & & & & & 0.01 \\
\hline Male & 713 & $53.2 \%$ & 619 & $86.8 \%$ & 94 & $13.2 \%$ & \\
\hline Female & 627 & $46.8 \%$ & 512 & $81.7 \%$ & 115 & $18.3 \%$ & \\
\hline Employment & & & & & & & 0.01 \\
\hline Employed full-time & 425 & $31.7 \%$ & 357 & $84.0 \%$ & 68 & $16.0 \%$ & \\
\hline Employed part-time & 120 & $9.0 \%$ & 96 & $80.0 \%$ & 24 & $20.0 \%$ & \\
\hline Self-employed & 99 & $7.4 \%$ & 88 & $88.9 \%$ & 11 & $11.1 \%$ & \\
\hline Not employed, but & 51 & $3.8 \%$ & 42 & $82.4 \%$ & 9 & $17.6 \%$ & \\
\hline \multicolumn{8}{|l|}{ looking for work } \\
\hline Not employed and & 18 & $1.3 \%$ & 10 & $55.6 \%$ & 8 & $44.4 \%$ & \\
\hline \multicolumn{8}{|l|}{ not looking for work } \\
\hline Retired & 433 & $32.3 \%$ & 381 & $88.0 \%$ & 52 & $12.0 \%$ & \\
\hline On disability & 107 & $8.0 \%$ & 80 & $74.8 \%$ & 27 & $25.2 \%$ & \\
\hline Student & 8 & $0.6 \%$ & 6 & $75.0 \%$ & 2 & $25.0 \%$ & \\
\hline Homemaker & 79 & $5.9 \%$ & 71 & $89.9 \%$ & 8 & $10.1 \%$ & \\
\hline Insurance status & & & & & & & 0.06 \\
\hline No health insurance & 459 & $34.3 \%$ & 375 & $81.7 \%$ & 84 & $18.3 \%$ & \\
\hline Health insurance & 881 & $65.8 \%$ & 756 & $85.8 \%$ & 125 & $14.2 \%$ & \\
\hline Race & & & & & & & 0.04 \\
\hline Non-white & 127 & $9.5 \%$ & 114 & $89.8 \%$ & 13 & $10.2 \%$ & \\
\hline White & 1213 & $90.5 \%$ & 1017 & $83.8 \%$ & 196 & $16.2 \%$ & \\
\hline Education & & & & & & & 0.84 \\
\hline $\begin{array}{l}\text { Less than college/ } \\
\text { university degree }\end{array}$ & 944 & $70.5 \%$ & 798 & $84.5 \%$ & 146 & $15.5 \%$ & \\
\hline College/university degree & 396 & $29.6 \%$ & 333 & $84.1 \%$ & 63 & $15.9 \%$ & \\
\hline \multicolumn{8}{|l|}{ Diagnosed comorbidity } \\
\hline Dyslipidemia & 571 & $42.6 \%$ & 478 & $83.7 \%$ & 93 & $16.3 \%$ & 0.55 \\
\hline Hypertension & 641 & $47.8 \%$ & 531 & $82.8 \%$ & 110 & $17.2 \%$ & 0.13 \\
\hline Obesity & 430 & $32.1 \%$ & 331 & $77.0 \%$ & 99 & $23.0 \%$ & $<0.001$ \\
\hline \multicolumn{8}{|l|}{ Health problems } \\
\hline \multicolumn{8}{|l|}{ in last 12 months } \\
\hline $\begin{array}{l}\text { Cardiovascular event } \\
\text { (eg, heart attack, stroke) }\end{array}$ & 39 & $2.9 \%$ & 29 & $74.4 \%$ & 10 & $25.6 \%$ & 0.15 \\
\hline Nausea or vomiting & 217 & $16.2 \%$ & 174 & $80.2 \%$ & 43 & $19.8 \%$ & 0.09 \\
\hline Constipation or diarrhea & 515 & $38.4 \%$ & 432 & $83.9 \%$ & 83 & $16.1 \%$ & 0.68 \\
\hline Weight gain & 343 & $25.6 \%$ & 267 & $77.8 \%$ & 76 & $22.2 \%$ & $<0.001$ \\
\hline \multicolumn{8}{|l|}{ Diabetes management steps } \\
\hline I try to maintain a healthy diet & 1054 & $78.7 \%$ & 877 & $83.2 \%$ & 177 & $16.8 \%$ & 0.01 \\
\hline $\begin{array}{l}\text { I try to maintain an } \\
\text { exercise regimen }\end{array}$ & 559 & $41.7 \%$ & 456 & $81.6 \%$ & 103 & $18.4 \%$ & 0.02 \\
\hline $\begin{array}{l}\text { I use a glucose monitor } \\
\text { and test strips }\end{array}$ & 835 & $62.3 \%$ & 693 & $83.0 \%$ & 142 & $17.0 \%$ & 0.06 \\
\hline Participated in diabetes & & & & & & & 0.03 \\
\hline \multicolumn{8}{|l|}{ educational program } \\
\hline Yes & 471 & $35.2 \%$ & 383 & $81.3 \%$ & 88 & $18.7 \%$ & \\
\hline No & 869 & $64.9 \%$ & 748 & $86.1 \%$ & 121 & $13.9 \%$ & \\
\hline
\end{tabular}

(Continued) 


\begin{tabular}{|c|c|c|c|c|c|c|c|}
\hline & \multicolumn{2}{|l|}{ Total } & \multicolumn{2}{|c|}{$\begin{array}{l}\text { Drug A (sitagliptin- } \\
\text { like profile) } \\
n=1 \text { I } 3 \text { | (84.4\%) }\end{array}$} & \multicolumn{2}{|c|}{$\begin{array}{l}\text { Drug B (liraglutide- } \\
\text { like profile) } \\
n=209(15.6 \%)\end{array}$} & \multirow[t]{2}{*}{$P$} \\
\hline & $\mathbf{n}$ & $\begin{array}{l}\text { \% of total } \\
\text { sample }\end{array}$ & $\bar{n}$ & Row \% & n & Row \% & \\
\hline \multicolumn{7}{|l|}{ Time of last $A_{1 C}$ test } & 0.42 \\
\hline Within the past 3 months & 823 & $61.4 \%$ & 691 & $84.0 \%$ & 132 & $16.0 \%$ & \\
\hline 4-6 months ago & 310 & $23.1 \%$ & 265 & $85.5 \%$ & 45 & $14.5 \%$ & \\
\hline $7-12$ months ago & 113 & $8.4 \%$ & 91 & $80.5 \%$ & 22 & $19.5 \%$ & \\
\hline Over a year ago & 59 & $4.4 \%$ & 53 & $89.8 \%$ & 6 & $10.2 \%$ & \\
\hline Never & 35 & $2.6 \%$ & 31 & $88.6 \%$ & 4 & $11.4 \%$ & \\
\hline \multicolumn{7}{|l|}{$\begin{array}{l}\text { What doctor said at last test } \\
\text { (of those who had a test) }\end{array}$} & 0.02 \\
\hline $\mathrm{A}_{\mathrm{IC}}$ was below the target & 220 & $16.4 \%$ & 188 & $85.5 \%$ & 32 & $14.6 \%$ & \\
\hline $\mathrm{A}_{\mathrm{IC}}$ was at the target & 533 & $39.8 \%$ & 466 & $87.4 \%$ & 67 & $12.6 \%$ & \\
\hline $\mathrm{A}_{\mathrm{IC}}$ was higher than the target & 371 & $27.7 \%$ & 293 & $79.0 \%$ & 78 & $21.0 \%$ & \\
\hline My physician did not provide & 83 & $6.2 \%$ & 67 & $80.7 \%$ & 16 & $19.3 \%$ & \\
\hline \multicolumn{8}{|l|}{ me with the lab results } \\
\hline \multirow[t]{2}{*}{ I don't remember } & 98 & $7.3 \%$ & 86 & $87.8 \%$ & 12 & $12.2 \%$ & \\
\hline & $\underline{M}$ & SD & $\mathbf{M}$ & SD & $\mathbf{M}$ & SD & $\mathbf{P}$ \\
\hline Age & 55.35 & 12.13 & 55.89 & 12.13 & 52.45 & 11.79 & $<0.001$ \\
\hline Years of T2DM diagnosed & 6.24 & 5.88 & 6.22 & 5.87 & 6.35 & 5.95 & 0.78 \\
\hline \multicolumn{8}{|l|}{ Importance of diabetes } \\
\hline \multicolumn{8}{|l|}{ medication attributes } \\
\hline \multicolumn{8}{|l|}{ (unimportant to important) } \\
\hline Side effects & 3.92 & 1.17 & 3.91 & 1.19 & 3.98 & 1.04 & 0.35 \\
\hline $\begin{array}{l}\text { Method of administration } \\
\text { (oral vs injectable) }\end{array}$ & 3.86 & 1.23 & 3.90 & 1.22 & 3.65 & 1.29 & 0.008 \\
\hline Effectiveness of medication & 4.49 & 0.84 & 4.47 & 0.85 & 4.55 & 0.77 & 0.26 \\
\hline Experience of prescribing & 4.11 & 0.96 & 4.10 & 0.97 & 4.13 & 0.85 & 0.67 \\
\hline \multicolumn{8}{|l|}{ physician with medication } \\
\hline Out-of-pocket costs & 3.42 & 1.43 & 3.42 & 1.43 & 3.43 & 1.46 & 0.94 \\
\hline of medication & & & & & & & \\
\hline
\end{tabular}

the sitagliptin-like profile were significantly lower, there was an overall preference for the sitagliptin-like profile in these subgroups (adjusted percentages for preferring the sitagliptin-like profile: those with obesity $=77.0 \%$ versus those without obesity $=87.9 \%$; those who experienced weight gain in the last year $=77.8 \%$ versus those who did not experience weight gain in the last year $=86.7 \%$; those with an $\mathrm{A}_{1 \mathrm{C}}$ above target $=79.0 \%$ versus those with an $\mathrm{A}_{1 \mathrm{C}}$ at $/$ below target $=86.5 \%$; those who tried to maintain an exercise regimen $=81.6 \%$ versus those who did not try to maintain an exercise program $=86.4 \%$ ). No other variable, including country, was a significant predictor of preference.

\section{Discussion}

Medication preferences for hypothetical sitagliptin-like and liraglutide-like agents were assessed in T2DM patients taking metformin monotherapy who would be eligible to add a new diabetes drug if they could not adequately control their blood sugar with metformin. Significantly more patients preferred the sitagliptin-like profile. Patients also were significantly more likely to prefer to take the drug with the sitagliptinlike profile first and more likely to report that they could take the drug with the sitagliptin-like profile as directed by their physician for a longer period of time. Among those who preferred the liraglutide-like profile, approximately one-third would have preferred the sitagliptin-like profile if the liraglutide-like drug was newer or more expensive. It is important to note that these preferences were consistent between wave 1 and wave 2 . Although wave 2 used a liraglutide-like profile with greater weight reduction and glycemic efficacy relative to wave 1 , this essentially had no effect on preferences.

Because of the liraglutide-like profile's weight loss and glycemic efficacy attributes, it was not surprising that a smaller proportion of patients with obesity, with weight gain in the last year, with $\mathrm{A}_{1 \mathrm{C}}$ values above target, or who tried to maintain an exercise regimen preferred the sitagliptin-like profile compared with those without obesity, without weight 
Table 5 Likelihood of preference for the drug with the sitagliptinlike profile (drug A) over the drug with the liraglutide-like profile (drug B)

\begin{tabular}{|c|c|c|}
\hline & OR $(95 \% \mathrm{CI})$ & $\mathbf{P}$ \\
\hline Germany & $0.82(0.48-I .4 I)$ & 0.47 \\
\hline France & $1.79(0.80-3.99)$ & 0.16 \\
\hline Italy & $1.92(0.97-3.79)$ & 0.06 \\
\hline Spain & $1.92(0.98-3.73)$ & 0.06 \\
\hline UK & $0.86(0.45-1.64)$ & 0.64 \\
\hline US (reference) & - & - \\
\hline Age & $1.02(1.01-1.04)$ & 0.003 \\
\hline Male & $1.30(0.93-1.80)$ & 0.12 \\
\hline White & $0.57(0.29-1.14)$ & 0.11 \\
\hline Employed $^{\mathrm{a}}$ & $1.08(0.76-1.53)$ & 0.67 \\
\hline Have health insurance & $1.26(0.75-2.12)$ & 0.39 \\
\hline Diagnosed hypertension & $0.99(0.71-1.39)$ & 0.96 \\
\hline Obesity & $0.54(0.38-0.75)$ & $<0.001$ \\
\hline Cardiovascular event in last year & $0.50(0.22-1.12)$ & 0.09 \\
\hline Nausea or vomiting in last year & $0.93(0.62-1.4 I)$ & 0.74 \\
\hline Weight gain in last year & $0.62(0.44-0.87)$ & 0.01 \\
\hline Maintain a healthy diet & $0.81(0.5 I-1.28)$ & 0.37 \\
\hline Maintain an exercise regimen & $0.68(0.49-0.96)$ & 0.03 \\
\hline $\begin{array}{l}\text { Use of glucose monitor } \\
\text { and test strips }\end{array}$ & $0.78(0.55-1.10)$ & 0.16 \\
\hline $\begin{array}{l}\text { Participated in diabetes } \\
\text { educational program }\end{array}$ & $0.83(0.59-1.16)$ & 0.27 \\
\hline $\mathrm{A}_{\mathrm{IC}}$ at or below target (reference) & - & - \\
\hline $\mathrm{A}_{\mathrm{IC}}$ above target & $0.59(0.4 I-0.83)$ & 0.006 \\
\hline$A_{I C}$ unknown/not remembered & $0.80(0.48-1.31)$ & 0.36 \\
\hline Importance of side effects & $1.01(0.86-1.18)$ & 0.91 \\
\hline $\begin{array}{l}\text { Importance of method } \\
\text { of administration }\end{array}$ & $1.32(1.15-1.52)$ & $<0.001$ \\
\hline $\begin{array}{l}\text { Importance of effectiveness } \\
\text { of medication }\end{array}$ & $0.79(0.62-1.01)$ & 0.05 \\
\hline $\begin{array}{l}\text { Importance of experience of } \\
\text { prescribing physician with medication }\end{array}$ & $0.93(0.77-1.13)$ & 0.49 \\
\hline $\begin{array}{l}\text { Importance of out-of-pocket } \\
\text { costs of medication }\end{array}$ & $1.00(0.88-1.13)$ & 0.98 \\
\hline
\end{tabular}

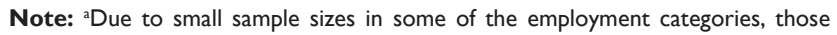
who were currently employed (full-time, part-time, or self-employed) were grouped together and compared with all other categories (which collectively served as the reference).

gain in the last year, with $\mathrm{A}_{1 \mathrm{C}}$ values at or below target, or who did not try to maintain an exercise regimen. Although these factors significantly increased the number of patients who preferred the liraglutide-like profile, the vast majority of patients still preferred the sitagliptin-like profile in these subgroups. Conversely, a higher proportion of patients who were older and who placed more importance on the method of administration preferred the sitagliptin-like profile compared with those who were younger and who placed less importance on the method of administration. These findings coincide with the stated reasons for preference, because the majority of those who preferred the sitagliptin-like profile ranked method of administration as the most important factor. Similarly, the majority of those who preferred the liraglutide-like profile ranked glycemic efficacy and weight loss as the most important factors. Overall, these findings suggest an overwhelming preference among T2DM patients for an oral medication with a profile like the DPP-4 inhibitor, sitagliptin, even with slightly lower glycemic efficacy and a neutral weight loss profile. When patients were given the opportunity to change their preference if the drug with the liraglutide-like profile was newer or more expensive, about one-third of patients did so. The results of our survey are generally consistent with the findings of a recent study by Jendle et al, which demonstrated that Swedish patients with T2DM were willing to pay considerable amounts of money to avoid injections and nausea, and to lose weight and achieve better efficacy. ${ }^{25}$

These results should also be considered within the context of recent health technology assessment agency activity. The National Institute for Health and Clinical Excellence (NICE) approved the use of liraglutide but, at the time of writing, only for a $1.2 \mathrm{mg}$ dosage and only when taken in conjunction with two other medications. ${ }^{26}$ The $1.2 \mathrm{mg}$ dosage would provide efficacy similar to that of the wave 1 profile and a lower efficacy than tested in the wave 2 profile. Yet, because preferences did not shift between the two waves, this recommended lower dosage would not likely have had any meaningful effect on our results. However, the liraglutidelike profile did not mention that two additional medications would be needed if it was selected, as would be the case given NICE's decision. It is conceivable that this could further reduce the preference for the liraglutide-like profile, although it is unclear to what extent.

Finally, it should be noted that full results of the headto-head trial of sitagliptin and liraglutide were reported after completion of our study. ${ }^{18}$ The blood glucose reduction and weight loss results were almost exactly what was found in the wave 2 survey. The incidence of nausea was $21 \%$ and $27 \%$ for liraglutide $1.2 \mathrm{mg}$ and $1.8 \mathrm{mg}$, respectively, versus $5 \%$ for sitagliptin, and the incidence of vomiting was $8 \%$ and $10 \%$ for liraglutide $1.2 \mathrm{mg}$ and $1.8 \mathrm{mg}$, respectively, versus $4 \%$ for sitagliptin. These values were slightly higher than those used in our survey (based on Nauck et al). ${ }^{22,23}$ The incidence of diarrhea was $7 \%$ and $11 \%$ for liraglutide $1.2 \mathrm{mg}$ and $1.8 \mathrm{mg}$, respectively, versus $5 \%$ for sitagliptin, and these values were slightly lower for liraglutide and slightly higher for sitagliptin than those used in our survey. Overall, however, the differences between the final study results and our assumptions based on the Novo Nordisk Interim Financial Report and the Nauck et al studies were small. ${ }^{22,23}$ In the head-to-head trial 
there was no difference in treatment satisfaction using the Diabetes Treatment Satisfaction Questionnaire between the liraglutide $1.2 \mathrm{mg}$ dose and sitagliptin, but there was a statistically significant difference in favor of liraglutide $1.8 \mathrm{mg}$ compared with sitagliptin $(+1.39 ; P<0.05)$. Important to consider, however, is that patients who agreed to participate in this open-label, head-to-head trial would have been willing to be randomized to an injectable medication; those patients who refused to accept injectable medication would not have been enrolled in this trial. The results of our study suggest that, in real clinical practice, a majority of patients on metformin monotherapy are not willing to take an injectable medication with an overall profile like liraglutide when an alternative like sitagliptin exists. Further research is clearly warranted.

Several limitations of this research should be considered. The sitagliptin and liraglutide profiles were simplified for purposes of a large, multinational, Internet-based survey. Although the clinical trials from which these profiles were derived noted no other statistically significant and/or clinically relevant side or other effects, it is conceivable that small, rare, or unknown effects of these drugs could impact treatment preference. Sitagliptin has been on the market for a few years and has more clinical trial evidence than liraglutide, which has just recently been launched. A pooled safety study of sitagliptin was published in 2010 after completion of our study ${ }^{27}$ That study combined results from 19 double-blind clinical studies $(n=5429$ exposed to sitagliptin and 4817 not exposed) with up to two years of follow-up. The pooled results suggest the risk of specific adverse events is similar in the sitagliptin-exposed and sitagliptin-nonexposed groups, except for hypoglycemia and diarrhea risk being greater in the nonexposed group (associated with sulfonylurea and metformin use, respectively) and constipation risk being greater in the sitagliptin-exposed group. All other adverse events were rare and/or of borderline or no statistical significance. Therefore, we feel the profile for sitagliptin is reasonably accurate in our study.

Patients with certain conditions (eg, thyroid cancer, chronic kidney disease) may not be eligible for certain medications or may be restricted in their dosage (which could have implications on the risk-benefit profiles). These types of factors were not included in the profiles and may have influenced the preferences for a select group of patients with those conditions.

In real clinical practice, the physician would provide the patient with information on the risks and benefits of the various treatment options and would be available to answer any questions the patient may have. The current study standardized the information presented. The actual experience of being on these medications may be difficult for patients to conceptualize from these survey profiles (and patients did not have the opportunity to clarify any ambiguity in the risks and benefits, as they could in a real-world environment). For example, the risk of nausea may be mitigated by physician instruction about proper titration, but this variability in nausea incidence could not be easily conveyed in a survey environment. Because of all of these factors, actual preference rates may be different from those reported here.

Finally, it is unclear to what extent the current sample of diabetes patients represents the general diabetes patient population on metformin monotherapy. Although the sample was geographically diverse, and the sampling structure of the NHWS (as a whole) mimics the demographic composition of individual countries, it is possible that our diabetes sample may differ in meaningful ways from the overall population.

\section{Conclusion}

In summary, patients preferred the sitagliptin-like profile to that of the liraglutide-like profile. These preferences were largely the same across Europe and the US. Because patients reported that they would be able to take the drug with the sitagliptin-like profile as directed by their physician for a longer period of time, further research is needed in order to determine the effect these preferences would have on treatment adherence and subsequent health outcomes.

\section{Disclosure}

Drs Girman, Brodovicz, Zhang, Qiu, Pentakota, and Radican are employees of Merck and Co., Inc., which provided funding to Kantar Health for the fielding and analysis of the current study. Dr DiBonaventura and Mr Wagner are employees of Kantar Health.

\section{References}

1. International Diabetes Federation (2009). IDF Diabetes Atlas. Available from: http://www.diabetesatlas.org/content/regional-overview. Accessed 2010 May 26.

2. Centers for Disease Control and Prevention. National diabetes fact sheet: General information and national estimates on diabetes in the United States, 2007. Available from: http://www.cdc.gov/diabetes/pubs/pdf/ ndfs_2007.pdf. Accessed 2010 May 26.

3. Stephens JM, Botteman MF, Hay JW. Economic impact of antidiabetic medications and glycemic control on managed care organizations: A review of the literature. J Manag Care Pharm. 2006;12(2):130-142.

4. American Diabetes Association. Standards of Medical Care in Diabetes 2010. Diabetes Care. 2010;Suppl 1:S11-S61.

5. Inzucchi SE. Oral antihyperglycemic therapy for type 2 diabetes: Scientific review. JAMA. 2002;287(3):360-372. 
6. Joy SV. Clinical pearls and strategies to optimize patient outcomes. Diabetes Educ. 2008;34 Suppl 3:54S-59S.

7. Brunton S. Beyond glycemic control: Treating the entire type 2 diabetes disorder. Postgrad Med. 2009;121(5):68-81.

8. Pollack MF, Purayidathil FW, Bolge SC, Williams SA. Patient-reported tolerability issues with oral antidiabetic agents: Associations with adherence; treatment satisfaction and health-related quality of life. Diabetes Res Clin Pract. 2010;87(2):204-210.

9. Marrett E, Stargardt T, Mavros P, Alexander CM. Patient-reported outcomes in a survey of patients treated with oral antihyperglycaemic medications: Associations with hypoglycaemia and weight gain. Diabetes Obes Metab. 2009;11(12):1138-1144.

10. Barron J, Wahl P, Fisher M, Plauschinat C. Effect of prescription copayments on adherence and treatment failure with oral antidiabetic medications. P T. 2008;33(9):532-553.

11. Yeaw J, Benner JS, Walt JG, Sian S, Smith DB. Comparing adherence and persistence across 6 chronic medication classes. J Manag Care Pharm. 2009;15(9):728-740.

12. Rodbard HW, Jellinger PS, Davidson JA, et al. Statement by an American Association of Clinical Endocrinologists/American College of Endocrinology consensus panel on type 2 diabetes mellitus: An algorithm for glycemic control. Endocr Pract. 2009;15(6):540-559.

13. Amori RE, Lau J, Pittas AG. Efficacy and safety of incretin therapy in type 2 diabetes: Systematic review and meta-analysis. JAMA. 2007; 298(2):194-206.

14. Zarowitz BJ, Conner C. The intersection of safety and adherence: New incretin-based therapies in patients with type 2 diabetes mellitus. Pharmacotherapy. 2009;29(12 Pt 2):55S-67S.

15. Khan H, Coyle FM, Chowdhury TA. Patients' preference for subsequent therapy following secondary failure of metformin and sulphonylurea. Pract Diabetes Int. 2009;26(7):282-284.

16. Hayes RP, Bowman L, Monahan PO, Marrero DG, McHorney CA. Understanding diabetes medications from the perspective of patients with type 2 diabetes: Prerequisite to medication concordance. Diabetes Educ. 2006;32(3):404-414.

17. Cooke CE, Lee HY, Tong YP, Haines ST. Persistence with injectable antidiabetic agents in members with type 2 diabetes in a commercial managed care organization. Curr Med Res Opin. 2010;26(1):231-238.
18. Pratley RE, Nauck MA, Bailey T, et al. Liraglutide versus sitagliptin for patients with type 2 diabetes who did not have adequate glycaemic control with metformin: A 26-week, randomised, parallel-group, openlabel trial. Lancet. 2010;375(9724):1447-1456.

19. Fine JT, Colditz GA, Coakley EH, et al. A prospective study of weight change and health-related quality of life in women. JAMA. 1999; 282(22):2136-2142.

20. Tiessen RG, Castaigne JP, Dreyfus JF, Nemansky M, Kruizinga HH, van Vliet AA. Pharmacokinetics and tolerability of a novel long-acting glucagon-like peptide-1 analog, CJC-1131, in healthy and diabetic subjects. Int J Clin Pharmacol Ther. 2008;46(9):443-452.

21. Bolge SC, Doan JF, Kannan H, Baran RW. Association of insomnia with quality of life, work productivity, and activity impairment. Qual Life Res. 2009;18(4):415-422.

22. Nauck MA, Meininger G, Sheng D, Terranella L, Stein PP. Efficacy and safety of the dipeptidyl peptidase-4 inhibitor, sitagliptin, compared with the sulfonylurea, glipizide, in patients with type 2 diabetes inadequately controlled on metformin alone: A randomized, double-blind, non-inferiority trial. Diabetes Obes Metab. 2007;9(2):194-205.

23. Nauck M, Frid A, Hermansen K, et al. Efficacy and safety comparison of liraglutide, glimepiride, and placebo, all in combination with metformin, in type 2 diabetes. Diabetes Care. 2009;32(1):84-90.

24. Nathan DM, Kuenen J, Borg R, et al. Translating the $A_{1 C}$ assay into estimated average glucose values. Diabetes Care. 2008;31(8): 1473-1478.

25. Jendle J, Torffvit $\mathrm{O}$, Ridderstråle $\mathrm{M}$, et al. Willingness to pay for health improvements associated with anti-diabetes treatments for people with type 2 diabetes. Curr Med Res Opin. 2010;26(4):917-923.

26. National Institute for Health and Clinical Excellence. NICE appraisal of liraglutide for type 2 diabetes mellitus. Available from: http://www. nice.org.uk/media/C2F/63/2010015Type2DiabetesLiraglutide.pdf. Accessed 2010 May 26.

27. Williams-Herman D, Engel SS, Round E, et al. Safety and tolerability of sitagliptin in clinical studies: A pooled analysis of data from 10,246 patients with type 2 diabetes. BMC Endocr Disord. 2010;10:7.
Patient Preference and Adherence

\section{Publish your work in this journal}

Patient Preference and Adherence is an international, peer-reviewed, open access journal focusing on the growing importance of patient preference and adherence throughout the therapeutic continuum. Patient satisfaction, acceptability, quality of life, compliance, persistence and their role in developing new therapeutic modalities and compounds to

\section{Dovepress}

optimize clinical outcomes for existing disease states are major areas of interest. This journal has been accepted for indexing on PubMed Central. The manuscript management system is completely online and includes a very quick and fair peer-review system. Visit http://www.dovepress.com/ testimonials.php to read real quotes from published authors. 